\title{
A Review on the Heat Treatment of Al-Si-Cu/Mg Casting Alloys
}

\author{
A.M.A. Mohamed and F.H. Samuel \\ Additional information is available at the end of the chapter
}

http://dx.doi.org/10.5772/79832

\section{Introduction}

The trend of the automotive industry goes toward the construction of high-powered, comfortable, economical, ecological and safe vehicles. A few $\mathrm{Al}$ alloys containing $\mathrm{Cu}$ and a few containing $\mathrm{Mg}$ and $\mathrm{Si}$ are heat treatable in the cast condition due to the precipitation strengthening mechanisms. Two of the major families of heat treatable aluminum alloys containing magnesium and silicon are the $6 x x x$ series in wrought aluminum alloys, and 3xx series in casting aluminum alloys. Al-Si-Cu/Mg alloys are well studied and there exists a lot of publication about the effect of alloying elements and solidification rate on the microstructure formation [1-3]. The influence of heat treatment on the mechanical properties including hardness and tensile strengths is also well studied, while the influence on plastic deformation behavior and elongation to fracture is less studied.

Although the benefit of heat treatment is undisputed, there exist several challenges for heat treatment operators, including market expectations of higher performance and reliability, lower production costs and energy use, as well as concern over environmental impacts. The heat treatment of age hardenable aluminum alloys involves solutionizing the alloys, quenching, and then either aging at room temperature (natural aging) or at an elevated temperature (artificial aging). The enhancement in mechanical properties after thermal treatment has largely been attributed to the formation of non-equilibrium precipitates within primary dendrites during aging and the changes occurring in $\mathrm{Si}$ particles characteristics from the solution treatment. The age hardening response depends on the fraction size, distribution and coherency of precipitates formed. Al-Si-Cu-Mg alloys and Al$\mathrm{Si}-\mathrm{Mg}$ alloys generally have a high age hardening response, while $\mathrm{Al}-\mathrm{Si}-\mathrm{Cu}$ alloys have a slow and low age hardening response. 


\section{Solidification process}

During the solidification from a melt, chemical thermodynamics and kinetics are generally considered in terms of the enthalpy and Gibbs free energy changes, the solidification path, composition changes, and phase transformations etc.. Chemical thermodynamics describes the most stable phases at equilibrium conditions (i.e. temperature, pressure, compositions etc.) relating to only the initial and final states of a system. Accordingly, the solidification rate in a metallurgical system can be estimated by the enthalpy $(\mathrm{H})$ and heat capacity $(\mathrm{Cp})$, and how these thermodynamic properties reflect the system thermal state and heat energy requirements. Chemical equilibrium is controlled by the Gibbs free energy $(\mathrm{G})$ of the system which is minimized for equilibrium conditions. In contrast, the dynamic system transformation between initial and final states controlled by chemical kinetics, indicates the path and phase changes of a chemical reaction in a system when the limited atomic movement (i.e. in solids, low temperatures, etc.) becomes dominant in a short process time. Hence the solidification rate under a real time condition will be greatly influenced by the nucleation efficiency and the atom diffusion between phases [4].

The solidification rate determines the coarseness of the microstructure including the fraction, size and distribution of intermetallic phases and the segregation profiles of solute in the $\alpha$-Al phase. Large and brittle intermetallic phases form during a slow solidification, which may initiate or link fracture, decreasing elongation to fracture. Additional, the defect size such as pore size, is also controlled to some extent by the solidification rate. The influence of defects on the elongation to fracture depends on their size, shape, distribution and fraction. Dendrite arms with smaller radius may remelt into the molten into the molten liquid along with the decreasing total interfacial energy. The Ostwaldripening effect on the formation of dendrite arm spacing (DAS) is determined by local solidification time, allowing smaller particles to grow and merge into the larger ones due to the reduced total surface energy in the system. DSA, which is proportional to (average cooling rate $)^{-n}$ where $n=1 / 2$ and $1 / 3$ for the primary and secondary dendrites respectively, generally ranging from 10 to $150 \mathrm{~mm}$ and which are controlled mainly by the solidification rate [5]. To gain an optimum property of an alloy, the DAS therefore must be minimized and distributed homogeneously.

The major phases in as-cast microstructure of Al-Si alloys are large size grains and primary $\alpha$ - $\mathrm{Al}$, acicular eutectic $\mathrm{Si}$, coarse primary $\mathrm{Si}$, and also other harmful intermetallic phases such as needle like $\beta$-Als $\mathrm{FeSi}$, with uncontrolled and unevenly distributed porosities etc. [6]. Table 1 summarizes the sequence of phase precipitation in hypoeutectic Al-Si alloys [7]. Al in the eutectic has been reported to have mainly the same crystallographic features as the primary $\alpha$-Al dendrites in unmodified alloys [8]. Figure 1.a indicates a basic structure of hypoeutectic Al-Si alloys consisting of grains (sizes at 1 10 mm in general), dendrites (typical DAS - 10 150 $\mu \mathrm{m}$ ), and eutectic Si which can be in acicular shapes as long as $2 \mathrm{~mm}$ or round particle as small as $1 \mu \mathrm{m}$. The acicular Si might be chemically modified to a fibrous morphology by using effective modifiers. 
Heterogeneous nucleation should be the major approach to refine the grains, which nucleate on some of the foreign nuclei sites and grow slowly in the melt. Effective grain refiners, such as $\mathrm{TiAl}_{3}$ and $\mathrm{TiB}_{2}$, must match their lattice perfect coherently to the $\mathrm{Al}$ matrix with their lattice coherencies (Figure 1.b). In contrast, particles with a poor lattice matching have little influence on increasing the nucleation of grains (Figure 1.c), resulting in an unrefined grain structure [9]. Typical examples of the microstructure of unmodified, Sr-modified, and Sb-modified alloys are shown in Figure 2.

\begin{tabular}{lll}
\hline Temperature $\left({ }^{\circ} \mathrm{C}\right)$ & Phases precipitated & Suffix \\
\hline 650 & Primary $\mathrm{Al}_{15}(\mathrm{Mn}, \mathrm{Fe})_{3} \mathrm{Si}_{2}$ (sludge) & Pre-dendrite \\
\hline 600 & Aluminum dendrites & Dendritic \\
& and $\left(\mathrm{Al}_{15}(\mathrm{Mn}, \mathrm{Fe})_{3} \mathrm{Si}_{2}\right)$ & Post-dendritic \\
& and $/ \mathrm{or}_{5} \mathrm{FeSi}$ & Pre-eutectic \\
\hline 550 & Eutectic $\mathrm{Al}+\mathrm{Si}$ & Eutectic \\
& and $\mathrm{Al} 5 \mathrm{FeSi}$ & Co-eutectic \\
& $\mathrm{Mg}_{2} \mathrm{Si}$ & \\
\hline 500 & $\mathrm{CuAl}_{2}$ and more complex phases & Post-eutectic \\
\hline
\end{tabular}

Table 1. Sequence of phase precipitation in hypoeutectic Al-Si alloys [7]

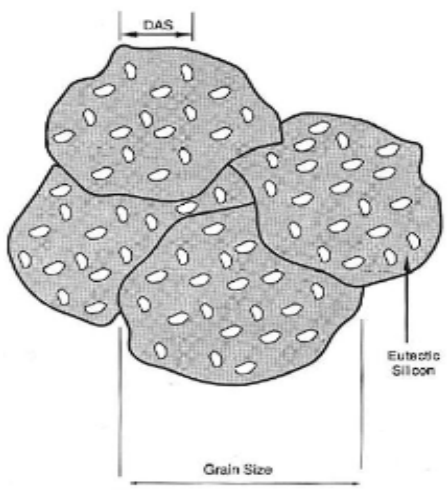

(a)

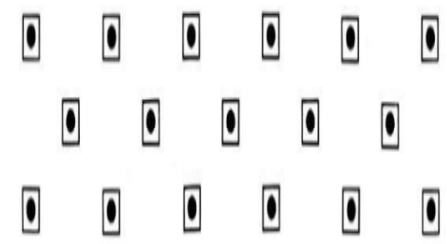

(b)

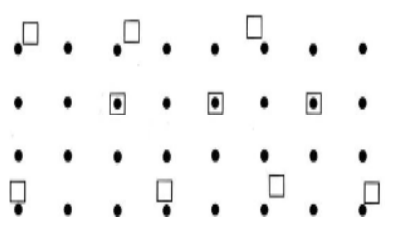

(c)

Figure 1. Schematics of a) Three essential elements (grains, Al dendrites, DAS, and eutectic $\mathrm{Si}$ in a basic hypoeutectic Al-Si microstructure; b) Perfect grain refiner particles (squares) with one to one lattice matching to $\mathrm{Al}$ atoms (points); c) Poor lattice matching [9]. 


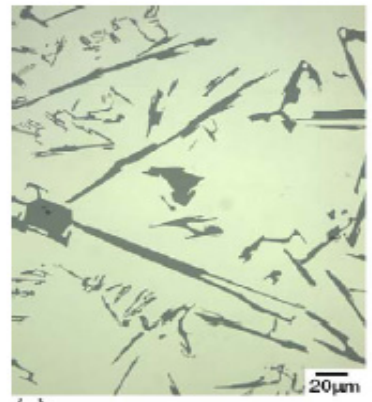

(a)

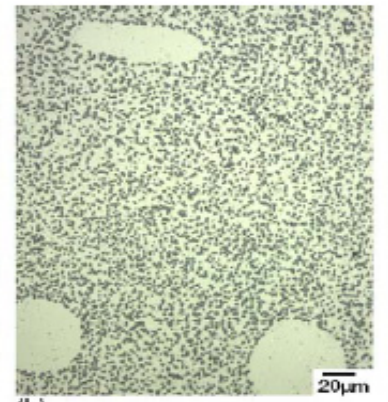

(b)

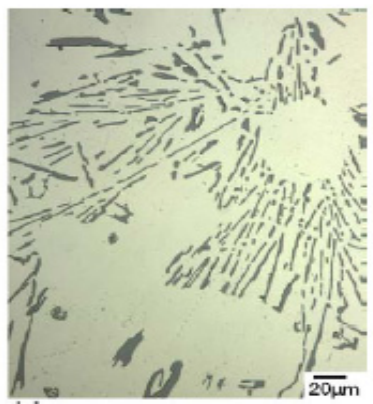

(c)

Figure 2. Comparison of the silicon morphology in: (a) unmodified; (b) Sr-modified (300 ppm Sr); and (c) Sb-modified (2400 ppm Sb), hypoeutectic aluminum-silicon alloys [10].

Copper forms an intermetallic phase with $\mathrm{Al}$ that precipitates during solidification either as blocky $\mathrm{CuAl}_{2}$ or as alternating lamellae of $\alpha-\mathrm{Al}+\mathrm{CuAl}_{2}$ [11]. During solidification, in the presence of iron, other copper containing phases form, such as $\mathrm{Cu}_{2} \mathrm{FeAl}_{7}$ or $\mathrm{Q}-\mathrm{Al}_{5} \mathrm{Cu}_{2} \mathrm{Mg} 8 \mathrm{Si}_{6}$ [12]. The $\mathrm{CuAl}_{2}$ phase can be blocky shape or finely dispersed $\alpha-\mathrm{Al}$ and $\mathrm{CuAl}_{2}$ particles within the interdendritic regions, as shown in Figure 3. The presence of nucleation sites, such as $\mathrm{FeSiAl}_{5}$ platelets or high cooling rates during solidification can result in fine $\mathrm{CuAl}_{2}$ particles [11]. The blocky $\mathrm{CuAl}_{2}$ phase particles are difficult to dissolve during solid solution heat treatment, unlike the fine $\mathrm{CuAl}_{2}$ phase particles that can dissolve within $2 \mathrm{hrs}$ solid solution heat treatment [13]. Magnesium is present as $\mathrm{Mg}_{2} \mathrm{Si}$ in $\mathrm{Al}-\mathrm{Si}-\mathrm{Mg}$ alloys if $\mathrm{Mg}$ is not in solution. $\mathrm{Mg}$ can also form a true quaternary compound $\mathrm{Cu}_{2} \mathrm{Mg}_{8} \mathrm{Si}_{6} \mathrm{Al}_{5}$ with other alloy elements in Al-319 alloy. In the absence of $\mathrm{Cu}$, high Fe and $\mathrm{Mg}$ result in the appearance of $\pi-$ $\mathrm{FeMg}_{3} \mathrm{Si}_{6} \mathrm{Al}_{8}$. The $\pi$ phase is difficult to dissolve during solid solution heat treatment [8].

(a)

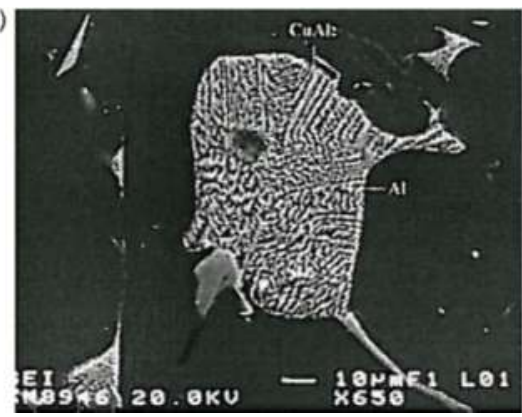

(b)

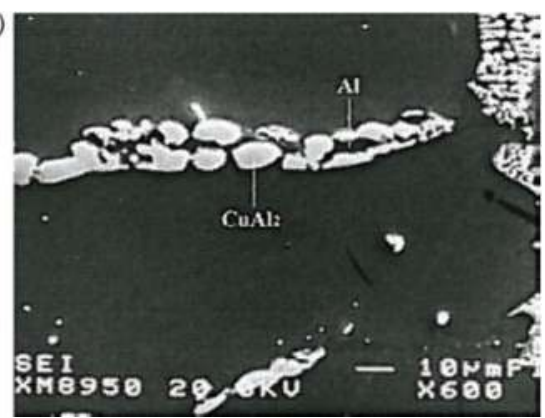

Figure 3. Cu-rich phases in as-cast 319 alloy: (a) Eutectic $\mathrm{Al}_{2} \mathrm{Cu}$ and (b) blocky $\mathrm{Al}_{2} \mathrm{Cu}$ [14].

A comparative study of the mechanical properties of $\mathrm{Al}-\mathrm{Si}-\mathrm{Cu}-\mathrm{Mg}$ alloys was carried out by Cáceres et al. [15] to investigate the effects of $\mathrm{Si}, \mathrm{Cu}, \mathrm{Mg}$, Fe, and $\mathrm{Mn}$, as well as solidification rate. The authors observed that increasing the $\mathrm{Cu}$ and $\mathrm{Mg}$ content generally resulted in an increase in strength and a decrease in ductility, whereas an increased Fe content (at an $\mathrm{Fe} / \mathrm{Mn}$ ratio of 0.5 ) dramatically lowered the ductility and strength of low-Si alloys. They 
also reported that the $\mathrm{Cu}+\mathrm{Mg}$ content of the alloys determines the precipitation strengthening and the volume fraction of the $\mathrm{Cu}$-rich and $\mathrm{Mg}$-rich intermetallics obtained.

Yi [16] adopt the enhanced solid diffusion coefficient of $\mathrm{Cu}$ in his model. The diffusion coefficient of $\mathrm{Cu}$ in $\alpha$-Al phase is increased by 4 -fold. The presence of Si-phase also has great influence on the diffusion of $\mathrm{Cu}$ in the matrix. It is assumed that the diffusion coefficient of $\mathrm{Cu}$ increases by 20 -fold due to the presence of Si-phase. The distribution of $\mathrm{Mg}$ and $\mathrm{Si}$ across the dendrite arm spacing also changes due to the increase of $\mathrm{Cu}$ diffusion in the matrix. This is attributed to the change of solidification path.

\section{Heat treatment of cast al alloys}

Heat-treatment is of major importance since it is commonly used to alter the mechanical properties of cast aluminum alloys. Heat-treatment improves the strength of aluminum alloys through a process known as precipitation-hardening which occurs during the heating and cooling of an aluminum alloy and in which precipitates are formed in the aluminum matrix. The improvement in the mechanical properties of $\mathrm{Al}$ alloys as a result of heat treatment depends upon the change in solubility of the alloying constituents with temperature. Figure 5 shows the major steps of the heat treatment which are normally used to improve the mechanical properties of aluminum. The alloy should first be solution treated at a temperature just below the eutectic temperature for long enough to allow solutionizing of the second phase. Then it should be quenched to room temperature. Finally it should be heated to a lower temperature to allow precipitation. Table 2 details a few of the more commonly applied heat treatments.

The T6 heat treatment is illustrated in Figure 4 for an Al-Si-Cu alloy as an example. The evolution of the microstructure is shown; from (1) atoms in solid solution at the solution treatment temperature, through (2) a supersaturated solid solution at room temperature after quench, to (3) precipitates formed at the artificial ageing temperature.

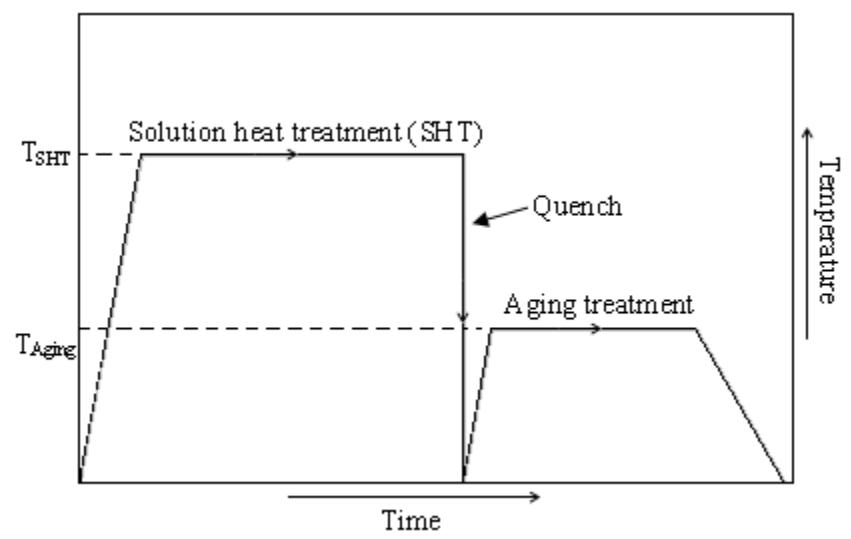

Figure 4. Diagram showing the three steps for precipitation hardening. 


\begin{tabular}{|c|c|c|c|}
\hline Treatment & Solution & Quench & Aging \\
\hline T4 & Yes & Yes & Room Temperature only \\
\hline T5 & No & No & Elevated Temperatures \\
\hline T6 & Yes & Yes & Elevated (to yield increased strength) \\
\hline T7 & Yes & Yes & Elevated (to yield dimensional stability) \\
\hline
\end{tabular}

Table 2. Common aluminum heat treatment designations

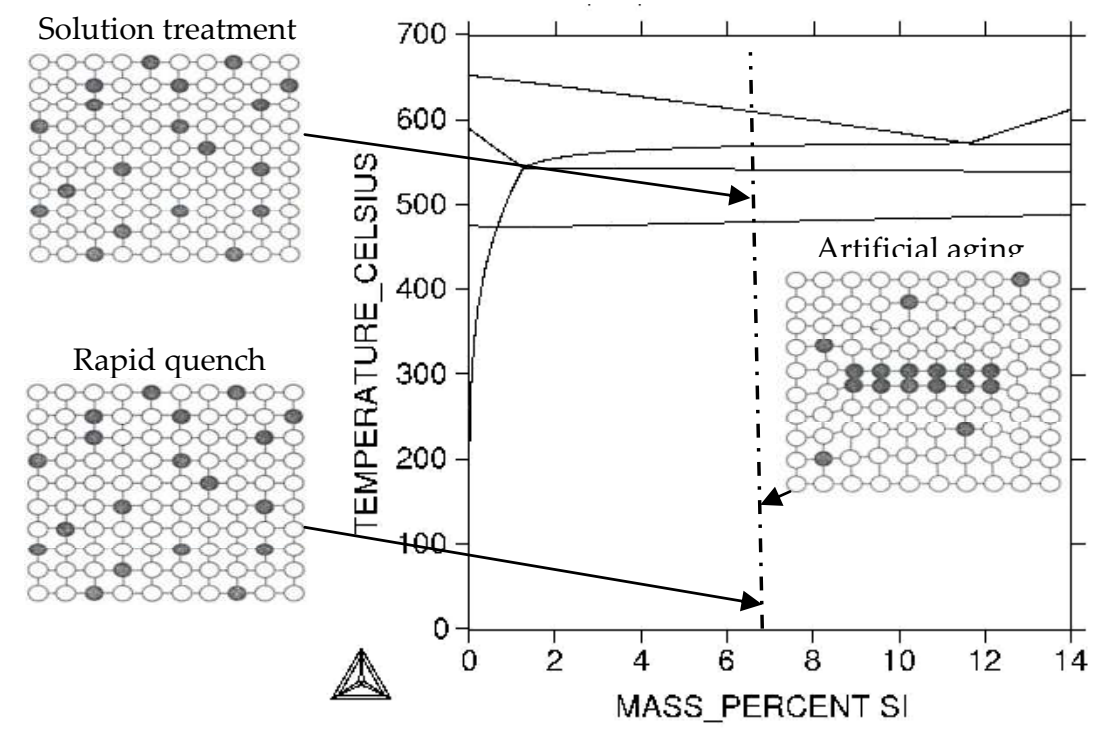

Figure 5. The T6 heat treatment process [17].

\subsection{Solution heat treatment}

Solution heat treatment must be applied for a sufficient length of time to obtain a homogeneous supersaturated structure, followed by the application of quenching with the aim of maintaining the supersaturated structure at ambient temperature. In Al-Si-Cu-Mg alloys, The solution treatment fulfils three roles: [18,19]

i. Homogenization of as-cast structure.

ii. Dissolution of certain intermetallic phases such as $\mathrm{Al}_{2} \mathrm{Cu}$ and $\mathrm{Mg}_{2} \mathrm{Si}$.

iii. Change of the morphology of eutectic silicon.

The segregation of solute elements resulting from dendritic solidification may have an adverse effect on mechanical properties. The time required for homogenization is determined by the solution temperature and by the dendrite arm spacing. Hardening alloying elements such as $\mathrm{Cu}$ and $\mathrm{Mg}$ display significant solid solubility in heat-treatable aluminum alloys at the solidus temperature; this solubility decreases noticeably as the temperature decreases. 
The changes in the size and morphology of the silicon phase have a significant influence on the mechanical properties of the alloy. It has been proposed that the granulation or spheroidization process of silicon particles through heat treatment takes place in two stages: (i) fragmentation or dissolution of the eutectic silicon branches and (ii) spheroidization of the separated branches [20]. During solution treatment, the particles undergo changes in size and in shape. In the initial stages, the unmodified silicon particles undergo necking and separate into segments, which retain their original morphology. As a result of the separation, the average particle size decreases and the fragmented segments are eventually spheroidized. The spheroidization and the coarsening of eutectic Si can occur concurrently during the second stage.

The solution treatment process needs to be optimized because too short a solution treatment time means that not all alloying elements added will be dissolved and made available for precipitation hardening, while too long a solution treatment means using more energy than is necessary. The solution heat treatment may be carried out in either a single step or in multiple steps. Single-step solution treatment is normally limited to about $495^{\circ} \mathrm{C}$, in view of the fact that higher temperatures lead to higher thermal stresses induced during quenching and the risk of the incipient melting of the Cu-rich phases [21-23]. This incipient melting tends to lower the mechanical properties of the casting. Solution treatment at temperatures of $495^{\circ} \mathrm{C}$ or less, however, is not capable of maximizing the dissolution of the copper-rich phases, nor is it able to modify the silicon particle morphology sufficiently. In Al-Si-Cu-Mg alloys having a low magnesium content (0.5 wt.\%), Ouellet et al. [24] used a solution temperature of $500^{\circ} \mathrm{C}$ because, at $505^{\circ} \mathrm{C}$, fusion of low melting point phases can occur; Wang et al. [25], on the other hand, reported that, for a similar alloy with a solution temperature of $520^{\circ} \mathrm{C}$, mechanical properties increase without any observable localized melting.

Based on conventional solution treatment rules, the solution temperature of $\mathrm{Al}-\mathrm{Si}-\mathrm{Cu}-\mathrm{Mg}$ alloys is restricted to $495^{\circ} \mathrm{C}$, in order to avoid incipient melting of the copper-rich phase $[26,27]$. The time at the nominal solution treatment temperature must be long enough to homogenize the alloy and to ensure a satisfactory degree of precipitate solution. In alloys containing high levels of copper, complete dissolution of the $\mathrm{Al}_{2} \mathrm{Cu}$ phase is not usually possible. The solution time must then be chosen carefully to allow for the maximum dissolution of this intermetallic phase, bearing in mind nevertheless, that solutions treating the alloy for long times are expensive and may not be necessary to obtain the required alloy strength. Moreover, the coarsening of the microstructural constituents and the possible formation of secondary porosity which result after prolonged annealing at such temperatures can have a deleterious effect on the mechanical properties [28].

Studies by Gauthier et al. [19] on the solution heat treatment of 319 alloy over a temperature range of $480^{\circ} \mathrm{C}$ to $540^{\circ} \mathrm{C}$, for solution times of up to 24 hours, showed that the best combination of tensile strength and ductility was obtained when the as-cast material was solution heat-treated at $515^{\circ} \mathrm{C}$ for 8 to 16 hours, followed by quenching in warm water at $60^{\circ} \mathrm{C}$. A higher solution temperature was seen to result in the partial melting of the copper phase, the formation of a structureless form of the phase and related porosity upon 
quenching, with a consequent deterioration of the tensile properties. A two-stage solution heat treatment suggested by Sokolowski et al. [29] is reported to reduce the amount of the copper-rich phase in the 319 alloys significantly, giving rise to better homogenization prior to aging and improving mechanical properties. Also, Crowell et al. [30] stated that the blocky $\mathrm{Cu}$ phase in $\mathrm{Al}-\mathrm{Si}-\mathrm{Cu}$ alloys dissolves with increasing solution time at the recommended solution temperature of $495^{\circ} \mathrm{C}$; also the rate of dissolution increases with $\mathrm{Sr}$ concentration.

A two-step solution treatment, namely, conventional solution treatment followed by a hightemperature solution treatment, as suggested by Sokolowski et al., [31, 32] is reported to reduce the amount of the copper-rich phase in 319 alloys significantly, thereby giving rise to better homogenization prior to aging and thus also to improvements in the mechanical properties. The holding time for the first stage and the solution temperature of the second stage are both significant parameters. Sokolowski et al. [32] studied the improvement in 319 aluminum alloy casting durability by means of high temperature solution treatment. Their results showed that a two-step solution treatment of $495^{\circ} \mathrm{C} / 2 \mathrm{~h}$ followed by $515^{\circ} \mathrm{C} / 4 \mathrm{~h}$ produced the optimum combination of strength and ductility compared to the traditional single-step solution treatment of $495^{\circ} \mathrm{C} / 8 \mathrm{~h}$.

Dissolve the micro-segregation of $\mathrm{Mg}$ and $\mathrm{Si}$ elements to form a supersaturated solid solution in the primary $\mathrm{Al}$ matrix in order to enable the formation of a large number of strengthening precipitates during subsequent natural and artificial ageing processes. Homogenize the casting, and attain a globular morphology of the eutectic Si phase to impart improved ductility and fracture toughness to the component. Reduce micro-segregation of other alloying elements in the primary $\mathrm{Al}$ matrix.

\subsection{Quenching}

Following solution heat treatment, quenching is the next important step in the heattreatment cycle. The objectives of quenching are to suppress precipitation during quenching; to retain the maximum amount of the precipitation hardening elements in solution to form a supersaturated solid solution at low temperatures; and to trap as many vacancies as possible within the atomic lattice [33,34].

The quench rate is especially critical in the temperature range between $450{ }^{\circ} \mathrm{C}$ and $200{ }^{\circ} \mathrm{C}$ for most Al-Si casting alloys where precipitates form rapidly due to a high level of supersaturation and a high diffusion rate. At higher temperatures the supersaturation is too low and at lower temperatures the diffusion rate is too low for precipitation to be critical. $4^{\circ} \mathrm{C} / \mathrm{s}$ is a limiting quench rate above which the yield strength increases slowly with further increase in quench rate [35-37].

Faster rates of quenching retain a higher vacancy concentration enabling higher mobility of the elements in the primary $\mathrm{Al}$ phase during ageing. An optimum rate of quenching is necessary to maximize retained vacancy concentration and minimize part distortion after quenching. A slow rate of quenching would reduce residual stresses and distortion in the 
components, however, it causes detrimental effects such as precipitation during quenching, localized over-ageing, reduction in grain boundaries, increase tendencies for corrosion and result in a reduced response to ageing treatment [38,39].

The best combination of strength and ductility is achieved from a rapid quenching. Cooling rates should be selected to obtain the desired microstructure and to reduce the duration time over certain critical temperature ranges during quenching in the regions where diffusion of smaller atoms can lead to the precipitation of potential defects [40]. The effectiveness of the quench is dependent upon the quench media (which controls the quench rate) and the quench interval. The media used for quenching aluminum alloys include water, brine solution and polymer solution [41-43]. Water used to be the dominant quenchant for aluminum alloys, but water quenching most often causes distortion, cracking, and residual stress problems [44,45]. It has been reported that the water temperature affects the properties of the cast aluminum alloy A356 subjected to T6 heat treatment once the water exceeds $60-70^{\circ} \mathrm{C}$, with UTS and YS being significantly more sensitive than ductility. Detailed TEM investigations on A356 alloy, reported elsewhere [46], revealed that, at the peak-aged condition and with a water quench at $25^{\circ} \mathrm{C}$, the $\alpha$ - $\mathrm{Al}$ matrix consists of a large number of needle-shaped and coherent $\beta^{\prime \prime}-\mathrm{Mg} 2 \mathrm{Si}$ precipitates. The size of the precipitates is approximately 3 to $4 \mathrm{~nm}$ in diameter and 10 to 20 in length. With a water quench at $60^{\circ} \mathrm{C}$, they observed how the density of the precipitates decreases and the size of the precipitates increases slightly; at the same time a significant number of fine Si precipitates resulting from precipitation of excess $\mathrm{Si}$ could be observed in the $\alpha$-Al matrix.

With a slow quenching in air, very different precipitation features are normally evidenced. By air quenching, the material remains at high temperatures for a longer period, which enhances the diffusion of silicon and magnesium. Besides a high density of fine $\beta^{\prime \prime}-\mathrm{Mg} 2 \mathrm{Si}$ precipitates, the $\alpha$-Al matrix also contained a large number of areas with coarse rods $\beta^{\prime}-$ $\mathrm{Mg} 2 \mathrm{Si}$ grouped parallel to each other [46]. While the first precipitates have an average size approximately 2 to $3 \mathrm{~nm}$ in diameter and around $40 \mathrm{~nm}$ in length, the latter show an average size $\sim 15 \mathrm{~nm}$ in diameter and $300 \mathrm{~nm}$ in length.

\subsection{Aging}

Age-hardening has been recognized as one of the most important methods for strengthening aluminum alloys, which involves strengthening the alloys by coherent precipitates which are capable of being sheared by dislocations [47]. By controlling the aging time and temperature, a wide variety of mechanical properties may be obtained; tensile strengths can be increased, residual stresses can be reduced, and the microstructure can be stabilized. The precipitation process can occur at room temperature or may be accelerated by artificial aging at temperatures ranging from 90 to $260^{\circ} \mathrm{C}$.

After solution treatment and quench the matrix has a high supersaturation of solute atoms and vacancies. Clusters of atoms form rapidly from the supersaturated matrix and evolve into GP zones. Metastable coherent or semi-coherent precipitates form either from the GP zones or from the supersaturated matrix when the GP zones have dissolved. The 
precipitates grow by diffusion of atoms from the supersaturated solid solution to the precipitates. The precipitates continue to grow in accordance with Ostwald ripening when the supersaturation is lost. The length of each step in the sequence depends on the thermal history, the alloy composition and the artificial ageing temperature.

The phenomenon of precipitation was originally discovered by Ardel in 1906 [48]. He found that the hardness of aluminum alloys which contained magnesium, copper, and other trace elements increased with time at room temperature, which was later explained by precipitation hardening. Over the years, much research was carried out to understand the aging kinetics of T4 and T6 heat treatments and to study the effects of underaging, peak-aging, and overaging on hardness [48-50], ultimate tensile strength, crack propagation behavior [51], and the cyclic stress-strain response of cast aluminum-silicon alloys [52].

The precipitation sequence for an Al-Si-Cu alloy, such as 319, is based upon the formation of $\mathrm{Al}_{2} \mathrm{Cu}$-based precipitates. The $\mathrm{Al}_{2} \mathrm{Cu}$ precipitation sequence is generally described as follows: [53-55]

$$
\alpha_{s S} \rightarrow \text { GP Zones } \rightarrow \theta^{\prime \prime} \rightarrow \theta^{\prime} \rightarrow \theta\left(\mathrm{Al}_{2} \mathrm{Cu}\right)
$$

The sequence begins with the decomposition of the solid solution and the clustering of $\mathrm{Cu}$ atoms; the clustering then leads to the formation of coherent, disk-shaped GP zones. At room temperature aging conditions, GP zones arise homogeneously; these zones manifest as two-dimensional, copper-rich disks with diameters of approximately 3-5 nm. As time increases, these GP zones increase in number while remaining approximately constant in size. With regard to the Al-Cu alloys, as the aging temperature is increased above $100^{\circ} \mathrm{C}$, the GP zones dissolve and are replaced by the $\theta^{\prime \prime}$ precipitate. This precipitate is a threedimensional disk-shaped plate having an ordered tetragonal arrangement of $\mathrm{Al}$ and $\mathrm{Cu}$ atoms; $\theta^{\prime \prime}$ also appears to nucleate uniformly in the matrix, and is coherent with the matrix in binary $\mathrm{Al}-\mathrm{Cu}$ alloys. The high degree of coherency causes extensive coherency-strain fields to arise [56], giving peak strength to the material at this time.

As aging proceeds, the $\theta^{\prime \prime}$ starts to dissolve, and $\theta^{\prime}$ begins to form by nucleating on dislocations and/or cell walls [54,55]; $\theta^{\prime}$ also has a plate-like shape and is composed of $\mathrm{Al}$ and $\mathrm{Cu}$ atoms in an ordered tetragonal structure; $\theta^{\prime}$ loses coherency with the matrix, however, as it grows. Thus, since the long-range coherency-strain fields do not arise, a decrease in strength properties may be observed, while continued aging causes the equilibrium $\theta\left(\mathrm{Al}_{2} \mathrm{Cu}\right)$ precipitate to occur. Tetragonal in shape, the $\theta$ phase is completely incoherent with the matrix; this fact, combined with its relatively large size and coarse distribution, reduces the strength properties significantly [56].

Increases in $\mathrm{Cu}$ were found mainly to reduce ductility and change the morphology of the $\mathrm{Cu}$-containing phases [57]. The strength of an age-hardenable alloy is governed by the interaction of moving dislocations and precipitates. The obstacles in precipitationhardened alloys which hinder the motion of dislocations may be either the strain field around the GP zones resulting from their coherency with the matrix, or the zones and 
precipitates themselves, or both. The dislocations are then forced to cut through them or go around them forming loops. The preceding thus implies clearly that there are three sources for age hardening: strain field hardening, chemical hardening and dispersion hardening. Gloria et al. [58] investigated the dimensional changes occurring during the heat treatment of an automotive 319 alloy by means of T6 and T7 tempers involving solution treatment, quenching and artificial aging. They observed that increasing the solution temperature has the greatest influence in the dimensional change of samples due to dissolution of the $\mathrm{Al}-\mathrm{Cu}(\theta)$ eutectic phase. By increasing the aging temperatures, however, expansion is produced as a result of the transformation of the metastable phases into equilibrium phases.

Shivkumar et al. [59] have studied the parameters which control the tensile properties of A356 alloy in the T6 temper. The improvement in the alloy strength has been attributed to the precipitation of negligible phases from a supersaturated matrix. The sequence of precipitation in Al-Si-Mg alloys, see Figure 5, can be described as follows:

i. Precipitation of GP zones, (needles about $10 \mathrm{~nm}$ long);

ii. Intermediate phase $\beta^{\prime \prime}-\mathrm{Mg}_{2} \mathrm{Si}$, (homogeneous precipitation);

iii. Intermetallic phase $\beta^{\prime}-\mathrm{Mg}_{2} \mathrm{Si}$, (heterogeneous precipitation);

iv. Equilibrium phase $\beta-\mathrm{Mg}_{2} \mathrm{Si}$, FCC structure $(\mathrm{a}=0.639)$, rod or plate-shaped.

The maximum alloy strength (peak-aging) is achieved just before the precipitation of the incoherent $\beta$-platelets. Apelian et al. [60] studied the aging behaviour of Al-Si-Mg alloys and observed that the precipitation of very fine $\beta^{\prime}-\mathrm{Mg}_{2} \mathrm{Si}$ during aging leads to a pronounced improvement in strength properties. Both aging time and temperature determine the final properties, see Figures 6 and 7. Their study also established that increasing the aging temperature by $10^{\circ} \mathrm{C}$ is equivalent to increasing the aging time by a factor of two. The effect of natural ageing on precipitation can be justified as follows. A high concentration of quenched in vacancies enhances the rate of solute clustering in the early stages of natural ageing, and this clustering of solute leads to a reduced supersaturation of solute in the matrix. The solute clusters have a fine distribution within the matrix, and if they were to act as successful nuclei for the formation of $\beta^{\prime \prime}$ during subsequent artificial ageing, a fine precipitate distribution would result. Evidently, this is not the case, a reason being that many of the clusters are below the critical size for stability at artificial ageing temperatures. Furthermore, a lower solute supersaturation is expected to reduce the kinetics of precipitation. Thus, during artificial ageing, the dissolution of unstable clusters increase the solute concentration, while larger clusters that are stable remove solute by growing into GP zones that become nucleation sites for $\beta^{\prime \prime}$. Therefore, the solute supersaturation is maintained at a relatively low level during artificial; ageing and the density of the $b^{\prime \prime}$ is much lower than that occurring in alloys without natural ageing.

The precipitation sequence for Al-Si-Cu-Mg alloys is similar, but more complex, as the $\mathrm{Q}^{\prime \prime}$ phase and the $\theta^{\prime}$ phase may also form. Cu can increase the fraction of the $\beta^{\prime \prime}$ phase formed, but it can also form the $Q^{\prime \prime}$ phase, which has a lower strength contribution compared to the 
$\beta^{\prime \prime}$ phase. The $\beta^{\prime \prime}$ phase is therefore preferred, rather than the $Q^{\prime \prime}$ phase. It is however not clearly stated when the $Q^{\prime \prime}$ phase forms at the expense of the $\beta^{\prime \prime}$ phase in cast alloys. For wrought alloys it has been shown that the fraction of the $Q^{\prime \prime}$ phase increases with natural ageing and artificial ageing time and temperature [64-66].

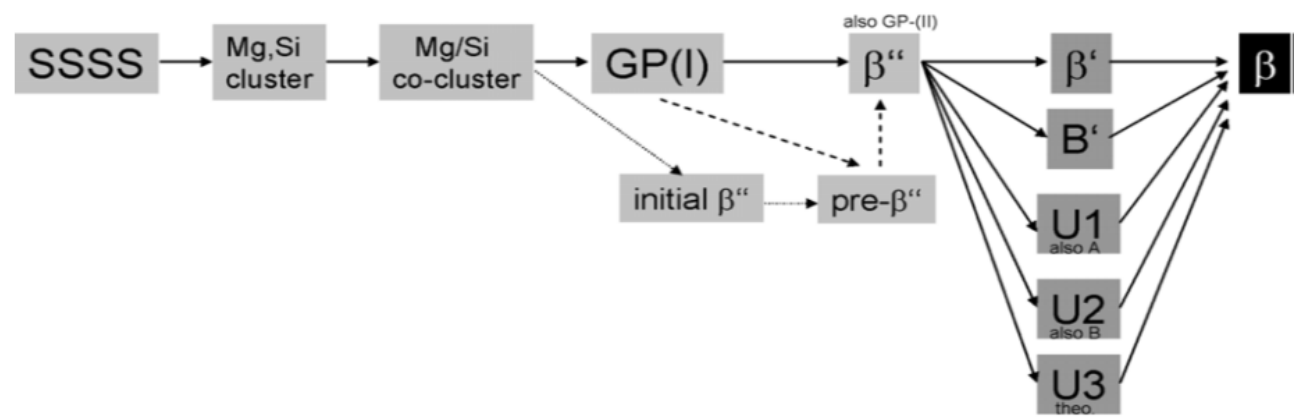

Figure 6. Sequence of phases found during age hardening of Al-Mg-Si alloys [60-62]. Supersaturated solid solution (SSSS) decomposes as $\mathrm{Mg}$ and $\mathrm{Si}$ atoms are attracted first to themselves (cluster) then to each other to form precipitates GP(I), sometimes also called initial- $\beta^{\prime \prime}$. GP(I) zones either further evolve directly to a phase $\beta^{\prime \prime}$ and then to a number of other metastable phases labelled $\beta^{\prime}, \mathrm{B}^{\prime}, \mathrm{U} 1, \mathrm{U} 2$ (another one, U3, has been postulated theoretically), or first form an intermediate phase called pre$\beta^{\prime \prime}$.
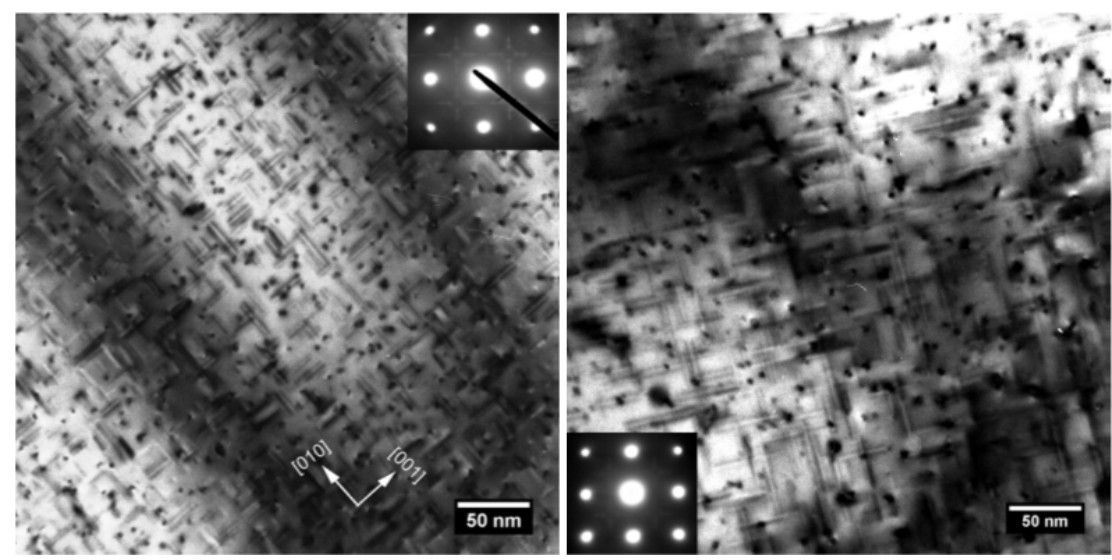

Figure 7. TEM images of Al-Si-Mg alloy subjected to 2 different heat treatments. (a) solutionising and quenching, immediate aging at $180^{\circ} \mathrm{C}$ for $540 \mathrm{~min}$, (b) solutionising and quenching, natural ageing for $10,000 \mathrm{~min}$ at $20^{\circ} \mathrm{C}$, aging at $180^{\circ} \mathrm{C}$ for $540 \mathrm{~min}$ [63].

The precipitation of metastable Mg-rich phases depends on the Mg-to-Si ratio. The excess of $\mathrm{Si}$ in solid solution can significantly alter the kinetics of precipitation and the phase composition. In other words, equilibrium phases are enriched in $\mathrm{Mg}$ and metastable phases are enriched in Si. Silicon precipitates are observed if stable phases are formed $[67,68]$. 

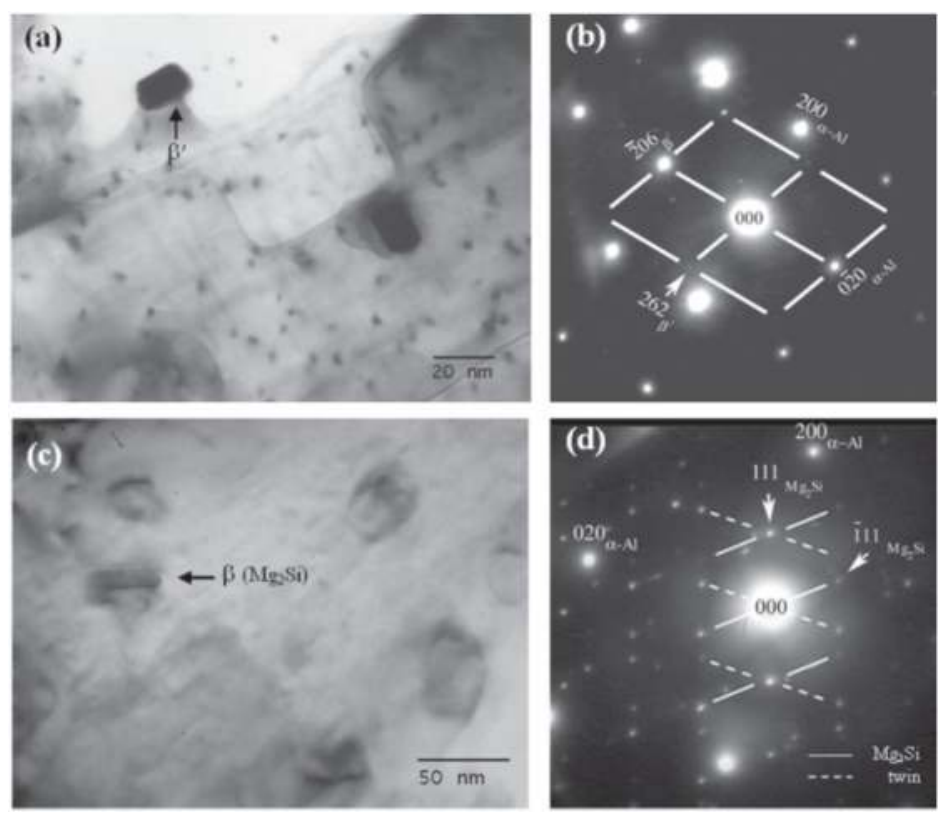

Figure 8. TEM-BF micrographs show precipitated phases in association with T6 over-ageing period; (a) 100 hours, (c) 300 hours. (b) and (d) are corresponding SADPs from (Mg2Si) particles indicated by the arrows in (a) and (c), respectively.

\section{Modelling of the heat treatment process}

Designing an alloy and a heat treatment process for a material that meets specified requirements for a certain component can be facilitated by the use of models. Development of models can also help in the search for new alloys as knowledge is gained about the influence of a specific part of the microstructure on the alloy properties. The first model where the yield strength is coupled to the evolution of the microstructure during artificial ageing was developed by Shercliff and Ashby in 1990 [69]. They defined their model as a mathematical relation between the process variables (e.g. alloy composition, heat treatment temperature and time), and the mechanical response of the alloy (e.g. yield strength, hardness), based on physical principles (e.g. thermodynamics, kinetics of precipitation, strengthening mechanisms etc.).

More refined models have been developed since then for prediction of yield strength $[70,71]$ and elongation to fracture [72] after artificial ageing. To be able to model the tensile strength after heat treatment, the evolution of the microstructure has to be modelled from casting to artificial ageing. Empirical equations as the Hollomon's [73] and the Ludwigson's [74] and equations where the parameters are coupled to the microstructure as in the KM strain hardening theory can be used to describe the plastic deformation behavior. The KM strain hardening theory has already been successfully used to couple the plastic deformation behavior to the microstructure for heat treatable wrought alloys and Al-Si-Mg casting alloys. 
The Scheil equation is a simple model giving fair results for segregation profiles and fraction of particles formed during solidification for aluminum alloys. The Scheil equation assumes no diffusion in the solid and complete diffusion in the liquid [75]. The correctness of the predictions of the Scheil segregation model depends on the diffusivity of the alloying elements in the $\alpha$-Al phase.

From the as-cast microstructure the time needed for dissolution and homogenization can be modelled. The model developed by Rometsch et al. [76], which handles solution treatment of Al-Si-Mg alloys, is an example of a simple, but efficient model. The evolution of the microstructure during artificial ageing involves nucleation, growth and coarsening. Two main approaches are used; precipitates having an average radius or precipitates having a size distribution. For the case of precipitates which a size distribution, coupled nucleation, growth and coarsening can be calculated, while for an average radius growth is sequentially followed by coarsening.

The strength of an alloy derives from the ability of obstacles, such as precipitates and atoms in solid solution, to hinder the motion of mobile dislocations. The strength contributions from atoms in solid solution and from shearable and non-shearable precipitates change during ageing, while contributions from lattice, dislocations and grain boundaries are constant. Small and not too hard precipitates are normally sheared by moving dislocations, see Figure 8.a. When the precipitates are larger and harder the moving dislocations pass the precipitates by bowing, leaving a dislocation ring around the precipitate, see Figure 8.b. The strength of the precipitates increases with size as long as it is sheared by dislocations. When dislocations pass the precipitates by looping, the alloy strength decreases with increasing radius of the precipitates. Figure 8.c shows the different strength contributions to the total yield strength for different ageing times.
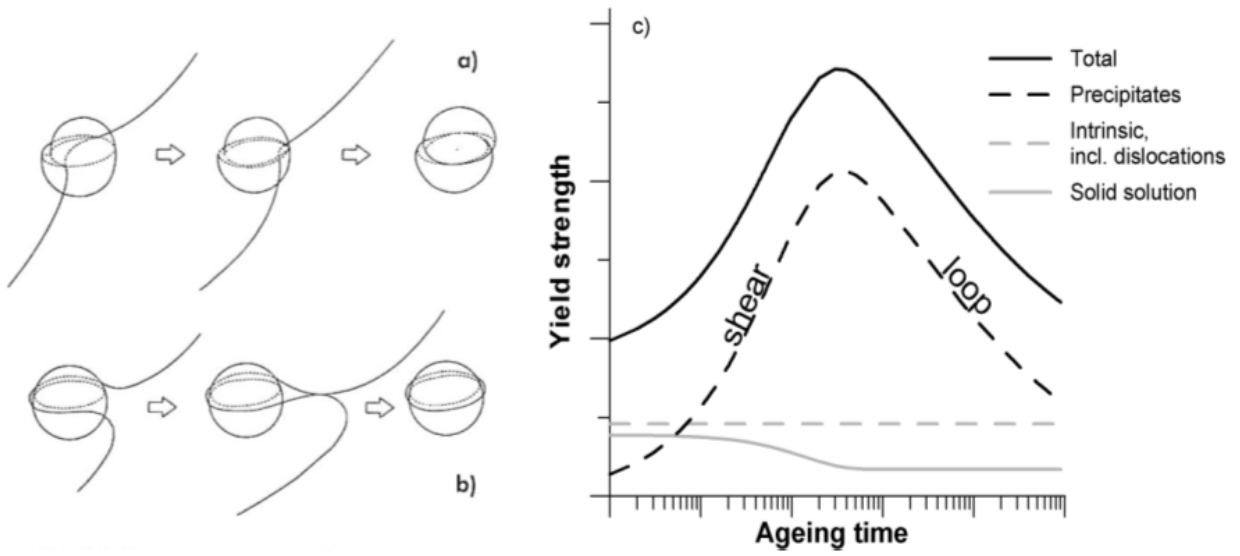

Figure 9. Dislocations passing a precipitate by a) shearing and b) looping (Orowan mechanism) [77] c) Illustrates the different strength contributions to the total yield strength 


\section{Conculsions}

Although many previous investigations into the thermal processing of $\mathrm{Al}-\mathrm{Si}-\mathrm{Cu} / \mathrm{Mg}$ casting alloys have been carried out, most focus on a single aspect of the overall process and a comprehensive experimental study considering all heat treatment stages is still required. This review shows that it is of vital importance to take the whole heat treatment process into consideration in order to achieve the optimal mechanical properties of an alloy. It is not sufficient to consider only the solution treatment and the artificial ageing parameters. Furthermore, the development of process models for the prediction of microstructure and mechanical property changes in aluminum alloys has focused on wrought alloys, while casting alloys that contain more complex microstructures have been overlooked and the evolution of the solution treated microstructure and its influence on subsequent ageing behaviour has not been incorporated into the models.

\section{Author details}

A.M.A. Mohamed

Materials Technology Unit (MTU), Qatar University, Doha, Qatar

Department of Metallurgical and Materials Engineering,

Faculty of Petroleum and Mining Engineering, Suez Canal University, Suez, Egypt,

F.H. Samuel

Université du Québec à Chicoutimi, Chicoutimi, Québec, Canada

\section{Acknowledgement}

The authors would like to thank Professor Mariam Al-Maadeed, Head of Materials Technology Unit, MTU, at Qatar University for her help and support.

\section{References}

[1] Mohamed A.M.A, Samuel F.H., Alkahtani S. Influence of $\mathrm{Mg}$ and Solution Heat Treatment on the Occurrence of Incipient Melting in Al-Si-Cu-Mg Cast Alloys. Journal of Materials Science and Engineering A 2012; A543 22-34.

[2] Mohamed A.M.A, Samuel A.M., Samuel F.H., Doty H.W. Influence of Additives on the Microstructure and Tensile Properties of Near-Eutectic Al-10.8\%Si Alloys. Materials and Design 2009;30(10) 3943-3957.

[3] Djurdjevic M., Stockwell T., Sokolowski J., 1999. The Effect of Strontium on the Microstructure of the Aluminium-Silicon and Aluminium-Copper Eutectics in the 319 Aluminium Alloy. Int. J. Cast Metal. Res. 1999;12 67-73.

[4] Stefanescu D. Casting, ASM International 1988, vol.15.

[5] Pekguleryuz M.O. Aluminum physical metallurgy. 2007.

[6] ASTM. (2006). Aluminum and Magnesium Alloys Annual (Volume 02.02). ASTM standards 
[7] Samuel A.M., Samuel F.H. Modification of Iron Intermetallics by Magnesium and Strontium in Al-Si Alloys. International Journal of Cast Metals Research 1997;10 147-157.

[8] Meyers C.W., Hinton K.H., Chou J.S. Towards the Optimization of Heat Treatment in Aluminum Alloys. Materials Sci Forum 1992;72 102-104.

[9] Gruzleski, J. E., \& Closset, B. M. (1990). The treatment of liquid Al-Si alloys. AFS inc.

[10] Dahle A., Nogita K., McDonald S., Dinnis C., Lu L. Eutectic Modification and Microstructure Development in Al-Si Alloys. Materials Science and Engineering A, 2005;413-414 243-248.

[11] Mondolfo L.F. Alumnium Alloys: Structure and Properties. Butter Worths 1976.

[12] Li Z., Samuel A.M. AFS Transactions. 2003;100 114-

[13] Adibhatla S. Master's Thesis, IMS, University of Connecticut 2003.

[14] Li Z., Samuel A.M., Samuel F.H., Ravindran C., Valtierra S. 2003. Effect of Alloying Elements on the Segregation and Dissolution of $\mathrm{CuAl}_{2}$ Phase in Al-Si-Cu 319 Alloys. J. Mater. Sci. 2003;38 1203-1218.

[15] Cáceres C.H., Svensson I., Taylor J. Strength-Ductility Behavior of Al-Si-Cu-Mg Casting Alloys in T6 Temper. International Journal of Cast Metals Research, 2003;15 721-726.

[16] Yi F. Computer Simulation of Solidification and Solution Treatment of Multiphase, Multicomponent Alloys. Master's Thesis, IMS, University of Connecticut 2005.

[17] Sundman B., Jansson B., Andersson J.O. Calphad 9, 1985; 153-190.

[18] J. Barresi, M.J. Kerr, H. Wang, M.J. Couper, “Effect of Magnesium, Iron, and Cooling Rate on Mechanical Properties of Al-7Si-Mg Foundry Alloys", AFS Transactions, 2000, 563-70.

[19] Gauthier J., Louchez P., Samuel F.H. Heat Treatment of 319.2 Al Automotive Alloy: Part 1, Solution Heat Treatment. Cast Metals 1995;8(1) 91-106.

[20] [20] F. Paray, J. Gruzleski, "Modification - A Parameter to Consider in the Heat Treatment of Al-Si Alloys", Cast Metals, 1993, vol. 5(4), pp. 187-198.

[21] J. Gauthier, P.R. Louchez and F.H. Samuel, Cast Metals (1994) 91-114.

[22] A.M.A Mohamed, A.M. Samuel, F.H. Samuel, H.W. Doty, Materials and Design, 30 (2009) 3943-3957.

[23] N. Crowell, S. Shivkumar, AFS Transactions 103 (1995) 721-726.

[24] P. Ouellet, F.H. Samuel, J. Mater. Sci. 34 (1999) 4671- 4697.

[25] P.S. Wang, S.L. Lee, J.C. Lin, J. Mater. Res .15 (2000) 2027-2035.

[26] P. Ouellet, F.H. Samuel, "Effect of Mg on the Ageing Behavior of Al-Si-Cu 319 Type Aluminum Casting Alloys" Journal of Materials Science, 1999, vol. 34(19), pp. 4671-4697.

[27] G. Wang, X. Bain, W. Wang, J. Zhang, "Influence of Cu and Minor Elements on Solution Treatment of Al-Si-Mg-Cu Cast Alloys", Materials Letters, 2003, vol. 57, pp. 4083-4087.

[28] L. Lasa, J. Ibabe, "Characterization of the Dissolution of the $\mathrm{Al}_{2} \mathrm{Cu}$ Phase in Two Al-SiCu-Mg Casting Alloys Using Calorimetry", Materials Characterization, 2002, vol. 48, pp. 371-378.

[29] J.H. Sokolowski, X.C. Sun, G. Byczynski, D.O. Northwood, D.E. Penord, R. Thomas, A. Esseltine, "A Metallurgical Study of the Heat Treatment of Aluminum Alloy 319 (Al-6Si3.5Cu) Castings", Journal of Materials Processing Technology, 1995, vol. 53(1-2), pp. 385-392.

[30] N. Crowell, S. Shivkumar, "Solution Treatment Effects in Cast Al-Si-Cu Alloys", AFS Transactions, 1995, vol. 103, pp. 721-726.

[31] J.H. Sokolowski, X-C. Sun, G. Byczynski, D.E. Penrod, R. Thomas, A. Esseltine, Journal of Materials Processing Technology, 53(1995) 385-392. 
[32] J.H. Sokolowski, M.B. Djurdjevic, C.A. Kierkus, D.O. Northwood, Journal of Materials Processing Technology, 109 (2001) 174-180.

[33] D. Apelian, S. Shivkumar, G. Sigworth, "Fundamental Aspects of Heat Treatment of Cast Al-Si-Mg Alloys", AFS Transactions, 1989, vol. 97, pp. 727-742.

[34] D.L. Zhang and L. Zheng, "The Quench Sensitivity of Cast Al-7 Wt Pct Si-0.4 Wt Pct Mg Alloy", Metallurgical and Materials Transactions A, 1996, vol. 27A, pp. 3983-3991.

[35] S. Seifeddine, G. Timelli, I.L. Svensson, Int. Foundry Res. 59 (2007) 2-10.

[36] D.L. Zhang, L. Zheng, Metall. Mater. Trans. A 27 (1996) 3983-3991.

[37] P.A. Rometsch, G.B. Schaffer, Int. J. Cast Metal. Res. 12 (2000) 431-439.

[38] IW. Martin, "Precipitation hardening (2nd ed.)", Butterworth-Heinemann, Oxford, UK(1998).

[39] J.T. Staley, "Quench factor analysis of aluminum alloys", Material Science and Technology,3 (1987), 923-935.

[40] D. Emadi, "Optimal Heat Treatment of A356.2 Alloy", Light Metals, The Minerals, Metals, and Materials Society, Warrendale, PA, 2003, pp. 983-989.

[41] T. Croucher, B. Butler, "Polymer Quenching of Aluminum Castings", $26^{\text {th }}$ National SAMPE Symposium, 1981, pp. 527-535.

[42] G.E. Totten and D.S. Mackenzie, "Aluminum Quenching Technology: A Review", Materials Science Forum, 2000, vols 331-337, pp. 589-594.

[43] A.V. Sverdlin, G.E. Totten, G.M. Vebster, "Polyalkyleneglycol Base Quenching Media for Heat Treatment of Aluminum Alloys" Metallovedenie Termicheskaya Obrabotka Metallov, 1996, vol. 6, pp. 17-19.

[44] O.G. Senatorova, "Low Distortion Quenching of Aluminum Alloys in Polymer Medium", Materials Science Forum, 2002, vols 396-402, pp. 1659-1664.

[45] H. Beitz, "None-Combustible Water-Based Quenchants in Forging Shops for Automotive Parts- Latest Development", The $1^{\text {st }}$ International Automotive Heat Treating Conference, Puerto Vallerta, Mexico, 1998, pp. 106-109.

[46] Zhang D.L. \& Zheng L. (1996). Quench sensitivity of cast Al-7 wt pct Si-0.4 wt pct Mg Alloy, Metallurgical and Materials Transaction A, Vol.27, No.12, pp. 3983-3991, ISSN 10735623

[47] H.M. Kandil, "Recent Development in Age Hardening Behaviour of Aluminum AlloysA Review Article", In Heat Treating: Proceeding of the 21 $1^{\text {st }}$ Conference, Indianapolis, Indiana: ASM International, 2001, pp. 343-351.

[48] A.J. Ardel, "Precipitation Hardening", Metallurgical Transactions A, 1985, vol. 16A, pp. 2132-65.

[49] A. Zanada, G. Riontino, "A Comparative Study of the Precipitation Sequences in Two AlSi7Mg Casting Alloys and their Composites Reinforced by $20 \% \mathrm{Al}_{2} \mathrm{O}_{3}$ Discontinuous Fibers", Materials Science Forum, 2000, vols 331-337, pp. 229-234.

[50] S. Kumai, "Hardness Characteristics in Aged Particulate", Scripta Metallurgica et Materialia, 1992, vol. 27, pp. 107-110.

[51] R.X. Li, "Age-Hardening Behavior of Cast Al-Si Base Alloy", Materials Letters, 2004, vol. 58, pp. 2096-2101.

[52] D.S. Jiang, L.H. Chen, T.S. Liu, "Effect of Aging on the Crack Propagation Behaviour of A356", Materials Transactions, JIM, 2000, vol. 41(4), pp. 499-506. 
[53] S.W. Han, "Effects of Solidification Structure and Aging Condition on Cyclic StressStrain Response in Al-7\%Si-0.4\%Mg Cast Alloys", Materials Science and Engineering A, 2002, vol. 337, pp. 170-178.

[54] A.D. Porter, K.E. Easterling, Phase Transformations in Metals and Alloys, Van Nostrand Reinhold, Berkshire, England, 1981.

[55] J.D. Verhoeven, Fundamentals of Physical Metallurgy, J. Wiley and Sons, New York, N.Y., 1975.

[56] W.F. Smith, Structure and Properties of Engineering Alloys, McGraw-Hill, New York, N.Y., 1981.

[57] J.E. Hatch, Aluminum: Properties and Physical Metallurgy, American Society for Metals, Metals Park, OH, 1984, pp. 50-51.

[58] F.H. Samuel, A.M. Samuel, H. Liu, "Effect of Magnesium Content on the Aging Behaviour of Water-Chilled Al-Si-Cu-Mg-Fe-Mn (380) Alloy Castings", Journal of Materials Science, 1995, vol. 30, pp. 1-10.

[59] A.M. Samuel, J. Gauthier, F.H. Samuel, "Microstructural Aspects of the Dissolution and Melting of $\mathrm{Al}_{2} \mathrm{Cu}$ Phase in Al-Si Alloys during Solution Heat Treatment", Metallurgical and Materials Transactions A, 1996, vol. 27A, pp. 1785-1798.

[60] D. Gloria, F. Hernandez, S. Valtierra, "Dimensional Changes During Heat Treating of an Automotive 319 Alloy", 20th ASM Heat Treating Society Conference Proceedings, 9-12 October 2000, St. Louis, MO, ASM International Materials Park, OH, 2000, pp. 674-679.

[61] S. Shivkumar, C. Keller, D. Apelian, "Aging Behaviour in Cast Al-Si-Mg Alloys", AFS Transactions, 1990, vol. 98, pp. 905-911.

[62] D. Apelian, S. Shivkumar, G. Sigworth, "Fundamental Aspects of Heat Treatment of Cast Al-Si-Mg Alloys", AFS Transactions, 1989, vol. 97, pp. 727-742.

[63] I. Polmear, Light Alloys, Butterworth-Heinemann, Amsterdam 2006 (4th ed.).

[64] M. A. van Huis, J. H. Chen, M. H. F. Sluiter, H. W. Zandbergen, Acta Mater. 2007, 55, 2183.

[65] R. Vissers, M. A. van Huis, J. Jansen, H. W. Zandbergen, C. D. Marioara, S. J. Andersen, Acta Mater. 2007, 55, 3815.

[66] X. Wang, S. Esmaeili, D.J. Lloyd, Metall. Mater. Trans. A 37 (2006) 2691-2699.

[67] D.G. Eskin, J. Mater. Sci. 38 (2003) 279-290.

[68] X. Wang, W.J. Poole, S. Esmaeili, D.J. Lloyd, J.D. Embury, Metall.Mater. Trans. A34(2003) 2913-2924.

[69] Maruyama N., Uemori R., Hashimoto N., Saga M., Kikuchi M. Scr. Mater. 1997;36 89-

[70] Zhen L., Fei W.D., Kang S.B., Kim H.W., J. Mater. Sci. 1997;32 1895

[71] H.R. Shercliff, M.F. Ashby, Acta Metall. Mater. 38 (1990) 1789-1802. [42] S. Esmaeili, D.J. Lloyd, W.J. Poole, Acta Mater. 51 (2003) 2243-2257.

[72] O.R. Myhr, O. Grong, S.J. Andersen, Acta Mater. 49 (2001) 65-75.

[73] J.D. Robson, Acta Mater. 52 (2004) 4669-4676.

[74] G. Liu, J. Sun, C.W. Nan, K.H. Chen, Acta Mater. 2005;53 3459-3468.

[75] J.H. Hollomon, Trans. AIME 162 (1945) 268-290.

[76] D.C. Ludwigson, Metall. Trans. 2 (1971) 2825-2828.

[77] D.M. Stefanescu, Science and Engineering of Casting Solidification, Kluwer Academic /Plenum Publisher, New York, 2002.

[78] P.A. Rometsch, L. Arnberg, D.L. Zhang, Int. J. Cast Metal. Res. 12 (1999) 1-8.

[79] V. Gerold, in: F.R.N. Nabarro (Ed.) Dislocations in solids, North-Holland, 1979, 222. 